\title{
O DIREITO SANCIONATÓRIO E O ESTADO REGULADOR NO PLANO ECONÓMICO-FINANCEIRO
}

\section{THE SANCTIONING LAW AND THE REGULATORY STATE IN ECONOMIC- FINANCIAL PLAN ${ }^{1}$}

\author{
Alexandra Vilela*
}

\begin{abstract}
RESUMO
Depois da crise económica-financeira de 2007-2008, com repercussões altamente negativas um pouco por todos os cantos do mundo, um grande número de Estados reagiu de forma musculada, visando sobretudo a atividade dos bancos e das seguradoras, e a das empresas. Essa reação traduziu-se, entre outros, na criação de um vasto leque de deveres a serem cumpridos no exercício de cada uma daquelas atividades profissionais, sob pena de incorrerem na prática de uma conduta ilícita (e logo sancionada) e na elevação do valor económico das sanções para patamares altíssimos e, muitas das vezes, difíceis de determinar. Paralelamente, o Estado Regulador consolidou-se onde já se encontrava e fixou-se em pontos onde ainda era desconhecido. Assim, com este pano de fundo, neste momento, alguns anos volvidos sobre a suprarreferida crise, julgamos pertinente tentar perceber a eficácia de tais medidas no plano económico-financeiro, bem como a das opções efetuadas por alguns Estados, como seja o português. No fundo, a questão que se nos coloca, e sobre a qual pretendemos refletir, prende-se com a eficácia do fortalecimento dos diferentes direitos sancionatórios e com a adoção de medidas como sejam os programas de compliance. A questão, a nosso ver, merece reflexão, porquanto, em Portugal, não só continuamos a discussão sobre qual a sanção que deve merecer a não implementação de programas daquele tipo, como também vemos engrossar, cada vez mais, a lista das infrações que podem ser praticadas pelos diferentes operadores económico-financeiros, sendo certo que, por vezes, é difícil identificar a sua natureza, mas são punidas com sanções de carácter económico elevadas. Um exemplo paradigmático do que vimos de referir encontramo-lo na Lei da Concorrência atualmente em vigor em Portugal que consagra crimes, contraordenações e infrações administrativas.
\end{abstract}

Palavras-chave: Estado Regulador. Direito Sancionatório. Crimes. Contraordenações.

\begin{abstract}
After the economic and financial crisis of 2007-2008, which had highly negative repercussions worldwide, a large number of States reacted forcefully, mainly targeting banks

Artigo submetido em 21 de setembro de 2021 e aprovado em 04 de dezembro de 2021.

1 Este artigo corresponde à tradução da versão inglesa, com pequenas alterações formais, apresentado e publicado em Inglês, na Economic and Social Development Conference (Porto, 16 e 17 de abril 2020)"ESD+ cujo link é: conference.com/upload/book_of_proceedings/Book_of_Proceedings_esdPorto2020_Online.pdf.

* Doutora em Direito pela Universidade de Coimbra, em Ciências Jurídico criminais. Professora Associada a tempo integral na Universidade Lusófona do Porto. E-mail: alexandra.vilela@ulp.pt; alexandra.m.vilela@gmail.com.
\end{abstract}


and insurance companies' activities, besides corporations. This reaction produced, mostly, a wide range of unlawful conduct-therefore sanctionable - and the economic value of sanctions will increase to higher levels - which are often difficult to determine. Regulatory State consolidated its position and simultaneously managed to settle at other points never reached so far. From that perspective, a few years after the crisis, we think it is relevant trying to understand the choices of some States - as the Portuguese-and the effectiveness of measures implemented in the economic and financial plans. The question that arise-and on which we intend to reflect - concerns the effectiveness of strengthening the different sanctioning rights and the adoption of measures as, for instance, compliance programs. In our view, this matter still needs reflection in Portugal, since we keep discussing the issue of which sanction must not integrate that kind of program. Meanwhile, the list of infractions - that different economic and financial operators may commit-continues to increase, and they are punishable with high economic sanctions, in spite of being difficult to identify their nature. A prime example of what we have just said is in the Competition Law (Lei da Concorrência), currently in force in Portugal, which enshrines crimes, administrative offences and infractions.

Keywords: Regulatory State. Sanctionatory Law. Crimes. Administrative offences.

\section{INTRODUÇÃO}

A crise económico-financeira de 2007-2008, com início nos Estados Unidos da América (EUA), veio a alastrar-se praticamente a todo o mundo, abrangendo a Europa. Tal crise surge no momento em que a europeização e a globalização do direito há muito constituíam uma realidade, ao mesmo tempo que, na Europa, já era do nosso conhecimento a experiência do Estado Regulador. Por tal motivo, a grande maioria dos Estados já não possui ordenamentos jurídicos isolados sem vasos comunicantes, como se verifica nos modelos operatórios atualmente em vigor na Europa, e mesmo em Portugal, os quais coincidem agora com os dos EUA. Basta pensar, por exemplo, nas agências reguladoras próprias do Estado Regulador que, oriundas dos EUA, posteriormente, haveriam de assentar arraiais na Europa. Deste modo, partindo do problema colocado pela europeização e pela globalização das legislações em matéria económico-financeira, e tendo como pano de fundo o Estado Regulador, iremos refletir sobre a eficácia da harmonização da legislação a nível global, bem como do tão propalado modelo do Estado Regulador na prevenção de uma nova crise. A nossa análise será, sobretudo, orientada para o direito português, chamando, por vezes, à liça o seu direito da concorrência.

\section{EM DIREÇÃO AO ESTADO REGULADOR. O CONTRIBUTO DA EUROPEIZAÇÃ̃O E DA GLOBALIZAÇÃO}

Nas palavras de Soares, a União Europeia (UE) e as suas antecessoras contribuíram para o fenómeno da europeização do direito. Isto porque, logo após a adesão de Portugal à Comunidade Económica Europeia (a então CEE e atual UE), se iniciou o fenómeno de receção desse direito, fruto de "alterações de relevo no funcionamento da economia, bem como no ordenamento jurídico nacional" (Soares, 2008, 37). A esse propósito, o mesmo autor diz-nos que o "sistema jurídico nacional constitui, porventura, um exemplo paradigmático do processo de europeização", sendo que a "adesão à Comunidade Europeia, e as obrigações daí resultantes, constituíram oportunidade para a modernização da ordem jurídica interna, com a adoção, e implementação, de diplomas normativos em áreas desconhecidas, ou em que se 
verificavam fortes resistências ao seu desenvolvimento". De igual modo, Soares destaca as importantes alterações ocorridas no direito aduaneiro, no direito fiscal, no direito das sociedades, por causa do direito comunitário. Acrescenta que a adesão à CEE deu origem, no ordenamento jurídico português, a outros ramos do direito, como seja o direito do ambiente, o direito dos consumidores e o direito da concorrência (Soares, 2008, 37 e 38). Por certo, a europeização do direito interno português não fica completa sem juntarmos aqui a influência decisiva da Convenção Europeia dos Direitos Humanos e da jurisprudência oriunda do seu respetivo tribunal.

Paralelamente e não menos importante do que a europeização dos ordenamentos jurídicos é a globalização. Com efeito, a globalização, "entendida num sentido lato como um processo económico, político, social e cultural", "veio acentuar que hoje, mais do que nunca, vivemos num mundo global e interdependente e que nenhum Estado pode estar isolado" (Teles, 2008, 99). A globalização veio, outrossim, contribuir para uma certa homogeneização dos direitos estaduais, daí resultando que os diferentes Estados passaram a adotar os mesmos instrumentos nos planos económico, financeiro, etc. Exemplo paradigmático do que referimos é a criação de entidades reguladoras, as quais atualmente se encontram presentes em quase todos os ordenamentos jurídicos europeus, próprias do Estado Regulador. Certos de que cada vez vivemos menos em ilhas jurídicas, mas, ao invés, em uma pequena aldeia global, vejamos algumas marcas daquele já designado Estado Regulador.

\subsection{Alguns traços fundamentais do Estado Regulador e a sua importância}

Não é possível, em estudo desta dimensão, fazermos um levantamento exaustivo daquilo a que designamos por Estado Regulador. No entanto, em traços gerais e como já tivemos oportunidade de escrever (Vilela, 2018, 102-105), é importante dizer que ele se caracteriza pelo facto de o Estado-Nação delegar um conjunto de poderes regulatórios justamente nas autoridades reguladoras, ao mesmo tempo que, ele, Estado, se abstém de intervir nesses mesmos setores. Com o Estado Regulador e as suas agências reguladoras, emerge um novo direito sancionatório, em grande medida produzido por essas agências. E essas agências, ao mesmo tempo, zelam pelo cumprimento desses deveres através de ações fiscalizadoras e do exercício de poderes sancionatórios. Mais tarde, a ele se veio associar, e depois a generalizar, um outro patamar de regulação, mais precisamente de autorregulação, através da implementação dos programas de compliance. Vejamos, no entanto, mais de perto, como chegámos a este novo modelo de Estado.

\subsubsection{O aparecimento e a disseminação das autoridades reguladoras. Breve nota quanto aos seus poderes. Os programas de compliance.}

Tendo em vista a explicação do Estado Regulador, Arnaud (2008, p. 86) começa por aludir à criação de um modelo de solução de problemas oriundo dos EUA, na passagem do século XIX para o XX, designado por governança. Segundo o autor, a governança é o "modo de se governar a si próprio" sem recorrer a atos ou diplomas legislativos do Estado propriamente dito e que depressa se tornou num modo particular de gestão de algumas matérias, sendo, ao mesmo tempo, um elemento fundamental da cultura jurídica norteamericana. Tal modo de solução dos problemas teve a sua razão de ser na distância sentida pelos dirigentes de alguns Estados face ao poder central, bem como na demora de uma tomada de decisão deste último. Assim, a governança, enquanto "processo complexo de tomada de decisão interactiva, dinâmica, projectiva, destinado a evoluir permanentemente para dar resposta a circunstâncias cambiantes" (Arnaud, 2008, p. 86 e 87), foi ganhando terreno, de tal forma que o Estado soberano passou a delegar uma parte das regulações em 
"instituições encarregadas de assegurar a regulação de espaços devolutos à liberdade do comércio" (Arnaud, 2008, p. 90), sendo ainda certo que a crise dos anos trinta do século passado, de acordo com o autor, veio a "favorecer a eclosão de uma verdadeira teoria da corporate governance (Arnaud, 2008, p. 87). Deste modo, o Estado assegurou uma nova resposta às mudanças que se verificaram nos "domínios das telecomunicações, do audiovisual, dos dados informáticos, do mercado da electricidade, dos seguros, da bolsa, dos mercados financeiros, da ética e da bioética, da protecção dos consumidores, da concorrência, da mediação, da protecção da infância", assim se criando, quase todos os dias, "uma nova autoridade de regulação num campo específico" (Arnaud, 2008, p. 90).

Daqui decorrre que as entidades reguladoras surgem em substituição de autoridades administrativas, tendo a incumbência de regular, inspecionar e sancionar um determinado setor económico, financeiro ou outro. E, se é certo que elas sofreram uma longa evolução nos Estados da sua origem (os EUA), também acabaram por chegar a outros Estados, fruto da mencionada europeização e globalização.

A existência deste tipo de instituições acarreta consequências no mundo jurídico, porque, por meio delas, se operam transformações no modo de produção do direito e porque são elas que têm o poder de sancionar as infrações que elas próprias investigaram. As entidades reguladoras criam, assim, vastos conjuntos de normas a observar no exercício de uma específica atividade. A este facto, acresce que elas também supervisionam, fiscalizam e sancionam severamente as infrações detetadas, sendo certo que a natureza das infrações é diferente de Estado para Estado, podendo, num deles, ser criado um crime para punir uma infração, noutro, uma contraordenação e, por fim, num terceiro, simplesmente infrações administrativas. Nesse enfiamento, assiste razão a Arnaud, quando assinala que a existência destas instituições cria uma "questão de compatibilidade entre o seu poder regulamentar e a própria autoridade pública (Arnaud, 2008, p. 90).

Atualmente, o quadro do Estado Regulador não fica completo se não juntarmos, ao já dito, a generalização de programas de compliance: tão importante como a heterorregulação, levada a cabo pelas autoridades reguladoras, é um outro plano de regulação, agora de autorregulação, e que se traduz na adoção, por parte das empresas, de "programas de cumprimento normativo voluntário (compliance programs)" com o intuito de reduzir significativamente "os riscos de responsabilização das sociedades comerciais e respectivos dirigentes nos âmbitos civil, contra-ordenacional e até criminal, e com isso, a defender genericamente os interessados (stakeholders)" (Mendes, 2018, p. 11).

\subsubsection{Breve traçado da Lei-Quadro das Entidades Reguladoras portuguesas}

Em Portugal, é sabido que já existiam, no ordenamento jurídico, autoridades administrativas com algumas afinidades relativamente às entidades reguladoras. Todavia, muito por causa da crise económico-financeira de 2007-2008 e dos seus reflexos em Portugal, o Estado português comprometeu-se, no Memorando de Entendimento (MoU) celebrado em maio de 2011, com os seus credores (FMI, UE e BCE, ou, abreviadamente, a troika), a aprovar a Lei-Quadro das Entidades Reguladoras, o que fez por meio da Lei n. ${ }^{\circ} 67 / 2013$, de 28/08. Através desse diploma legal, foi criado um regime comum aplicável aos diferentes reguladores, contribuindo para a uniformização do quadro legal já existente quanto à regulação. Além disso, Morais salienta que esta lei era necessária, entre outros motivos, porque contribuía para a uniformização do regime legal das entidades reguladoras, já que algumas se situavam "na administração indirecta, outras na administração independente, outros num limbo híbrido de uma administração semi-independente onde se registavam diferenças nos repectivos vínculos em relação ao Governo" (Morais, 2015, p. 156). 
Segundo o autor, a existência destas entidades reguladoras justificava-se, na medida em que se impunha a "substituição de um paradigma de Estado que intervinha directamente no mercado" por um outro paradigma de Estado que interviesse o "mínimo indispensável para que o mercado financeiro funcionasse, que salvaguardasse o interesse público e que supervisionasse por via indireta os agentes económicos". E, ao mesmo tempo, era premente a criação de tais entidades dotadas de "elevada especialização técnica, despolitização e imparcialidade". Fazendo prova da europeização do direito e, de um modo geral, da sua globalização, Morais chama ainda a atenção para a influência da UE, no sentido da criação de reguladores independentes dos respetivos Estados (Morais, 2015, p. 156).

É certo que, através das entidades reguladoras, e em particular através desta lei, se almejou a sua independência perante a administração estadual. Contudo, Morais coloca o dedo na ferida ao esclarecer que essas entidades reguladoras não possuem independência face às "suas estruturas homólogas de cúpula a nível europeu", razão pela qual "esta política da UE constitui uma forma desta última limitar a soberania estadual, através de uma administração paralela ou separada" (Morais, 2015, p. 157).

Sem dúvida que um dos traços fundamentais a destacar destas entidades é efetivamente a sua elevada especialização técnica, o que não só é desejável, como é louvável a todos os títulos, nomeadamente, porque as questões que lhes competem resolver são dotadas de um alto grau de conhecimentos técnicos, e só assim poderão litigar de igual para igual com os infratores da respetiva área de intervenção (Vilela, 2017, p. 130). Na verdade, se bem vemos o problema, os infratores de qualquer área regulada não apresentam qualquer semelhança com o cidadão comum que viola uma norma do Código da Estrada ou que não paga o seu imposto no prazo estipulado. Bem ao contrário. Estamos na presença de infratores com um elevado grau de conhecimentos específicos da área em que se movem, conhecimentos altamente qualificados quer sob o ponto de vista técnico, quer até científico. Por isso, qualquer atividade de fiscalização, inspeção ou instrução e de condenação requer que, do outro lado, o lado de quem aprecia, levanta os autos, instrui e decide, estejam técnicos tão preparados ou mais ainda do que os infratores. Só assim a luta contra as infrações se pode travar com igualdade de armas. Do mesmo modo e por esta mesma ordem de razões, saudamos, outrossim, a criação do Tribunal da Concorrência, Regulação e Supervisão, medida que constava igualmente do MoU (Vilela, 2017, p. 130).

Todavia, como já salientámos, não podemos deixar de referir que as entidades reguladoras, nos termos do artigo $3 .^{\circ}$ da Lei n. ${ }^{\circ}$ 67/2013, mais precisamente do seu $n .^{\circ} 2$, alínea e), possuem "poderes de regulação, de regulamentação, de supervisão, de fiscalização e de sanção de infrações". Ora, daqui resulta que as entidades reguladoras concentram todo um conjunto de poderes que fazem delas entidades poderosas e nas quais deverão existir cautelas para "que o órgão da entidade reguladora que fiscaliza e que levanta o auto de infracção não deva ser aquele que a aprecia e que a julga, assim se acolhendo uma solução apontada por Ribeiro e com a qual concordamos" (Vilela, 2017, p. 130). É assim fundamental que a fiscalização do cumprimento da legislação seja efetuado de forma eficaz para evitar novos danos seja em que sector for. Todavia, chegada a hora de o procedimento passar da fase da investigação para a sancionatória, não se pode aceitar, em um Estado de Direito material, que o órgão que controla uma e outra fase seja o mesmo. Com esta ideia, apenas pretendemos fazer a defesa de um processo acusatório mitigado, em que os infratores tenham a garantia de imparcialidade, no âmbito das fases de investigação e sancionamento, o que não se logra alcançar quando o órgão que investiga e aplica a sanção é o mesmo. Aliás, pugnando por uma solução ainda mais drástica nesta matéria, salientamos, uma vez mais, Mendes, para quem deve existir uma separação total entre a autoridade que investiga e aquela a quem pertence o poder decisório em matéria de direito das contraordenações (Mendes, 2009, p. 223 e ss.). 
Em síntese, e dizendo-o com Mendes, a entrada em cena "das autoridades independentes subverteu o clássico modelo de separação de poderes", na medida em que elas "foram dotadas de três tipos de poderes públicos, tradicionalmente separados, a saber: poderes normativos, executivos e (para)judiciais" (Mendes, 2018, p. 18). Seja como for, não podemos deixar de ser apologistas da existência destas entidades reguladoras, e o facto é que elas, para serem verdadeiramente eficazes nos objetivos que preconizam, devem estar munidas de poderes musculados e deter o poder de impor o cumprimento de deveres cuja violação seja considerada uma infração severamente sancionada com sanções, por maioria de regra, pecuniárias. A não ser assim, estas instituições, destituídas de poder, de pouco ou nada serviriam. Bem se vê, pois, que não estamos a defender os seus poderes de forma ilimitada, sobretudo nos casos onde estejam em causa direitos fundamentais. Repare-se, por exemplo, que há muito defendemos que algumas sanções acessórias mais gravosas, aplicadas no âmbito do processo organicamente administrativo, não devem ser aplicadas pelas autoridades administrativas (agora pelos reguladores), mas pelos tribunais (Vilela, 2013, p. 376). Ora, se assim pensávamos quanto à aplicação de algumas sanções acessórias mais gravosas, também, por maioria de razão, entendemos, agora, que o mesmo pode acontecer em outros casos no decurso do processo contraordenacional, na fase que decorre perante o regulador. No entanto, a este particular problema voltaremos adiante.

\subsubsection{O ordenamento jurídico sancionatório emergente do Estado Regulador}

\subsubsection{Algumas especificidades do direito interno português: o direito das contraordenações}

Para melhor se compreender tudo o quanto vem de ser dito, revela-se importante introduzir um pequeno apontamento sobre o direito contraordenacional. Na verdade, uma grande percentagem das infrações que fazem parte do direito do Estado Regulador revestem a natureza de contraordenação. Esta, no nosso entendimento, possui uma natureza jurídica diferente da do crime, o que equivale a dizer que não é um crime menor. Mas também não é uma infração de carácter administrativo. Não. Ela é, por assim dizer, uma infração que cada vez mais se aproxima do direito penal e que o elegeu como direito subsidiário, bem como ao direito processual penal. O direito das contraordenações encontra-se previsto no Decreto-Lei n. ${ }^{\circ}$ 433/82, de 27 de outubro, que aprovou o Regime Geral das Contra-Ordenações (RGCO). Sob o ponto de vista processual, divide-se em uma fase que decorre perante uma autoridade administrativa (fase que designamos por fase organicamente administrativa) e, presentemente, também perante os reguladores (artigos $33 .^{\circ}$ a 58. ${ }^{\circ}$ ). E uma segunda fase que se inicia, ou não, consoante o arguido se conforme (ou não) com a decisão condenatória proferida por aquela autoridade administrativa, ou por aquele regulador (artigo 59. a $75 .^{\circ}$ ). Nessa hipótese, poderá, então, impugnar judicialmente a decisão para um tribunal, aí se iniciando uma segunda fase do processo contraordenacional, mais precisamente a fase judicial (artigos 59. ${ }^{\circ}, 60 .^{\circ}$ e $61 .^{\circ}$ ). Mais dois ou três traços para que fique claro que se trata de um direito garantístico, como deve ser em um Estado Regulador, com sanções económicas pesadíssimas e sanções acessórias não menos graves: vigora o princípio da legalidade quanto às contraordenações e quanto às coimas, bem como o princípio da proibição da retroatividade em matéria de aplicação da lei no tempo (artigo 3..$^{\circ}$ ); o arguido tem direito de defesa (artigo 50..$^{\circ}$ ) e, relativamente a todo o despacho ou medida que lhe sejam desfavoráveis, o arguido tem o direito de recorrer a um tribunal a fim de que ele sindique a legalidade da medida. Existe, portanto, uma ampla possibilidade de impugnações judiciais e, em consequência, de fazer intervir um juiz: por esta via, permite ao arguido recorrer judicialmente de decisões, despachos e medidas tomadas contra si (artigo 55. $)$; e tem ainda direito a impugnar judicialmente a decisão, havendo hipótese de não a aceitar. Reiteramos o que acima dissemos: 
os seus direitos subsidiários são o direito penal, quanto às questões materiais ou substantivas (artigo 32. ${ }^{\circ}$ ). E quanto ao direito processual penal, quer na fase organicamente administrativa, quer na fase de impugnação judicial, é sempre o direito processual penal o seu direito subsidiário (artigo 41..$^{\circ}$ (Vilela, 2015, p. 154).

\subsubsection{O direito sancionatório emergente do Estado Regulador}

Feita esta ressalva que julgamos importante quanto ao direito interno português, quanto à existência da contraordenação, ilícito que Portugal "importou" do ordenamento jurídico alemão, vejamos, agora, o direito sancionatório deste Estado.

No que se refere ao direito resultante deste novo modelo de Estado, assistimos a modificações que, em alguns casos, poderíamos classificar de inéditas. Desde logo, começando pelo direito penal, direito sancionatório por excelência e de ultima ratio, podemos afirmar que o direito penal emergente deste novo modelo de Estado apresenta-se-nos com contornos bem diferentes face ao que nos foi legado pelo Iluminismo: o direito penal deste "novo" Estado protege essencialmente bens jurídicos supraindividuais, muitos deles criados em função da atividade exercida e sem qualquer semelhança com aqueles que encontramos no âmbito do direito penal clássico ou de justiça.

Neste novo Direito Penal, mais do que punir um dano, revela-se necessário prevenir riscos, porque aguardar pela verificação de um dano no seio de uma atividade, por exemplo, financeira, pode determinar uma intervenção demasiado tardia, na medida em que um vasto conjunto de empresas, de operadores económicos e de consumidores já sofreu "na própria pele" os efeitos da violação desse dever ou dessa conduta, devido aos danos causados pela infração. Além de que esses danos podem, como se viu no passado, provocar uma crise sistémica. E, "para o bem e para o mal", a globalização - como acima vimos - provoca este efeito de contágio não só dos efeitos positivos, como também dos negativos. Aliás, foi justamente por causa da globalização que os efeitos da crise económico-financeira de 20072008, iniciada nos EUA, se repercutiram em quase todo o globo. Dizíamos, então, que este novo direito penal, no essencial, constrói crimes de perigo, muitas vezes crimes de perigo abstrato, caracterizados pelo facto de o legislador, na hora de elaborar o respetivo tipo legal de crime, pura e simplesmente, presumir que aquela conduta é, em abstrato, perigosa. Em retas contas, isto significa que a sanção penal é aplicada em momento anterior - talvez demasiado anterior - àquele em que era suposto produzir-se o dano ao bem jurídico protegido (Vilela, 2018, p. 102), o que implica também uma antecipação da tutela penal. Ainda característico deste direito penal é o recurso frequente a normas penais em branco, i.e., normas que carecem de outras para que o sentido das primeiras fique completo.

Na preciosa síntese de Silva Sánchez (2015, p. 2 e 3), de quem, em parte, nos temos vindo a socorrer, as infrações paradigmáticas deste tipo de Estado são o incumprimento dos deveres impostos pelo Regulador, destinados à prevenção de riscos e em que o fundamento da aplicação da pena radica numa ideia utilitarista, sem que exista a preocupação de observar o princípio do merecimento de pena (Silva Sánchez, 2015, e Vilela, 2018, p. 103 e 104), cânone fundamentalíssimo no direito penal do bem jurídico que ainda defendemos.

\subsubsection{Um exemplo colhido do Direito da Concorrência português}

Ilustrativo do que vimos de dizer é, por exemplo, o direito da concorrência, atualmente contido no Novo Regime Jurídico da Concorrência (RJC), aprovado pela Lei n. ${ }^{\circ}$ 19/2012, de 5 de junho, na sequência da celebração do já mencionado MoU celebrado em maio de 2011 entre o Estado Português e a troika. Com efeito, a evolução sofrida no direito da concorrência permite-nos encontrar nele, primeiro, a influência da europeização e do direito comunitário e, 
depois, a da regulação própria do Estado Regulador, a qual se acentuou depois da crise económica-financeira de 2007-2008, quando Portugal celebrou o MoU com a troika.

Com efeito, embora Portugal já conhecesse o direito da concorrência em momento anterior ao do RJC, o certo é que foi apenas no ano de 2003 que se operou uma grande reforma nesse setor. Assim, por um lado, entrou em vigor a Lei n..$^{\circ}$ 18/2003, de 11 de junho, que aprovou a Lei da Concorrência e, por outro, o Decreto-Lei n..$^{\circ}$ 10/2003, de 18 de janeiro, que instituiu um dos "braços" do Estado Regulador, a Autoridade da Concorrência (AdC). Esta foi dotada de poderes de inspeção, investigação e sanção das infrações praticadas, possuindo uma jurisdição de carácter universal, já que exerce "os poderes que lhe foram confiados em todos os sectores da actividade económica" (Soares, 2008, p. 45, bem como Vilaça e Gomes, 2017, p. 103 e 104). Nas palavras de Vilaça e Gomes, estes dois diplomas constituíram um salto qualitativo no âmbito do direito da concorrência português, passando a alinhar, no essencial, "com os critérios predominantes no regime em vigor na Comunidade Europeia e nos países europeus mais avançados neste domínio" (Vilaça e Gomes, 2017, p. 104).

Não se ficou por aqui a aproximação do direito da concorrência aos outros direitos estrangeiros, pois, após a crise económica-financeira, o Estado Português reformou novamente a legislação sobre o direito da concorrência, como acima se referiu. Estreitemos, portanto, a nossa análise quanto ao objeto do presente estudo e olhemos para este ramo do direito regulado pós-crise mais de perto.

\section{E DEPOIS DA CRISE? O QUE ACONTECEU NO (E COM O) ESTADO REGULADOR?}

A crise económico-financeira iniciada em 2007-2008, nos EUA, depressa se alastrou à Europa, sendo certo que, para alguns autores, ela se ficou a dever a um défice de supervisão dos reguladores. Afinal, não obstante já conhecermos a existência das agências reguladoras, parece que elas haviam exercido os seus poderes ora de um modo pouco vigoroso, ora com alguma incúria. Assim, era preciso tonificar esses mesmos poderes e, ao mesmo tempo, pensar em outras formas de sancionar os ilícitos cometidos no âmbito dos setores regulados.

Deste modo, Portugal, submerso em uma crise, viu-se obrigado a recorrer a um resgate financeiro junto da troika e a assinar o já mencionado MoU, em maio de 2011, do qual constavam medidas que passavam por intensificar a regulação dos supervisores, bem como por blindar as atividades reguladas com um aumento significativo de deveres a observar pelas diferentes empresas. Segundo Costa, do acordo assinado, fazia parte, em um primeiro momento, a obrigatoriedade de Portugal aprovar o designado Plano de Estabilidade e Crescimento (PEC I) 2008-2011, no qual se encontravam, entre outras medidas, a necessidade de reforço dos "deveres de informação e transparência das instituições financeiras e da garantia dos depósitos, a concessão de garantias pessoais pelo Estado aos bancos e o reforço da sua solidez financeira". Ainda com a mesma autora, por entre esses deveres de informação e transparência, existia o de prestação de informação às autoridades de supervisão, o reforço da informação disponível sobre produtos complexos, a obrigação de comunicação às autoridades de supervisão quanto às participações detidas (Costa, 2014, p. 11), sendo que alguns destes se encontram agora plasmados no artigo $210 .^{\circ}$ do Regime Geral das Instituições de Crédito e Sociedades Financeiras (RGICSF).

As obrigações decorrentes para o setor da banca e dos seguros não divergiram em muito do que resultou para o direito da concorrência. Assim, de um jeito exemplificativo, vejamos o que resultou deste novo direito da concorrência. 


\subsection{O direito da concorrência português depois da crise económico-financeira}

No âmbito da concorrência, o MoU traçou como objetivos ao Estado Português, entre outros, o reforço da concorrência e dos reguladores setoriais. Ao mesmo tempo, propôs a revisão da respetiva lei da concorrência "tornando-a o mais autónoma possível do Direito Administrativo e do Código de Processo Penal e mais harmonizada com o enquadramento legal da concorrência da UE" (MoU, 2011, p. 34).

Dentro deste enfiamento, foi então aprovado o novo RJC, sendo pertinente ressaltar de tal diploma, por entre muitas outras, as notas que passamos a destacar. Assim, começamos por indicar que o artigo 67. ${ }^{\circ}$ do RJC classifica as infrações ao direito da concorrência como contraordenações ressalvando, todavia, a possibilidade de existir responsabilidade criminal e de poderem ser adotadas medidas administrativas. Consequentemente, e depois de classificar a maioria das suas infrações como contraordenações, ilícito que se distingue do penal, mas que também não pertence ao direito administrativo, o legislador deste mesmo regime institui o RGCO como direito subsidiário no âmbito dos processos sancionatórios relativos a práticas restritivas (artigo 13. ${ }^{\circ}$ ) e a operações de concentração de empresa. Institui igualmente o RGCO como direito subsidiário aplicável na segunda fase do processo contraordenacional (artigo 83..$^{\circ}$ ), fase que se caracteriza, como vimos, por decorrer não perante a autoridade reguladora, mas perante um juiz. Não obstante, apesar do anteriormente referido, segundo o RJC, aplica-se o Código do Procedimento Administrativo (CPA) ao procedimento de controlo de operações de concentração de empresas (artigo 42..$^{\circ}$ ) e à interposição de recursos no âmbito dos procedimentos administrativos previstos nesta lei (artigo 91. ${ }^{\circ}$ ).

Prosseguindo com as notas a salientar relativamente ao actual RJC, refira-se, igualmente, que se mantém a previsão das sanções pecuniárias compulsórias (artigo 72..$^{\circ}$ ), mecanismo oriundo do direito civil e alheado quase sempre do direito sancionatório, sendo igualmente pertinente referir a previsão dos procedimentos de transação no inquérito, previstos no artigo 22. ${ }^{\circ}$.

Outro conjunto de normas introduzidas por este mesmo diploma legal que merecem igual reflexão são as que dizem respeito à determinação das coimas. Assim, e desde logo sob o ponto de vista da determinação da medida da coima, o atual artigo $69 .^{\circ}$ do RJC sofreu alterações de monta face ao seu antecessor. Isto porque, enquanto o artigo $43 .^{\circ}$ da lei anterior fixava os valores máximos da coima por referência a uma percentagem "do volume de negócios do ano anterior", agora, os números 2,3 e 4 do artigo $69 .^{\circ}$ fixam o valor máximo da coima igualmente com recurso a uma percentagem "do volume de negócios realizado através de uma "percentagem do volume de negócios realizado no exercício imediatamente anterior à decisão". E, mais grave ainda, de acordo com o n. 8 do artigo ora em causa, a AdC tem o poder de adotar "linhas de orientação contendo a metodologia a utilizar para aplicação das coimas, de acordo com os critérios definidos na presente lei. Em matéria de sanções, nos artigos $75 .^{\circ}$ a $82 .^{\circ}$, encontramos a previsão do designado direito de clemência que permite, sob a verificação de alguns pressupostos, aos agentes das infrações beneficiarem da dispensa ou da redução da coima por infrações às regras da concorrência.

Que dizer, enfim, destas exemplificativas alterações à lei da concorrência, ocorridas após a crise económico-financeira de 2007-2008?

\subsection{O reforço efetivo do Estado Regulador, mas também uma aproximação do direito sancionatório a alguns mecanismos não próprios desse mesmo direito sancionatório}

Acreditamos que o reforço dos deveres nas diferentes atividades reguladas contribuiu para a superação da crise, e entendemos, como aliás o fizemos desde um primeiro momento, que a regulação forte e efetiva só poderia contribuir para o melhor funcionamento dos 
respetivos setores regulados. Pensamos, pois, que o Estado Regulador foi intensificado não só na sua dimensão de heterorregulação, como também na de autorregulação. Basta pensar, por exemplo, na infinidade de deveres que a troika nos fez introduzir no setor bancário, como atrás vimos e que fazem parte do artigo $210 .^{\circ}$ RGICSF. Com efeito, aí encontramos normas que, em última análise, bem poderiam ser consideradas integrantes de um programa de compliance (Vilela, 2018, p. 120).

Todavia, o direito regulador pós-crise, em geral, veio introduzir alguns elementos estranhos aos direitos sancionatórios e, outras vezes, criou ou intensificou desarmonias jurídicas, por força do apelo ora ao direito das contraordenações, ora ao direito penal, para solucionar alguns problemas.

Por isso, e antes de adentrarmos na análise a que nos propusemos, é bom que tenhamos presente que, do direito sancionatório por excelência, fazem parte, entre outros, o direito penal e o direito contraordenacional, sendo certo que ambos possuem natureza jurídica diferente. É bom ainda termos presente que, para além do ordenamento jurídico alemão, apenas o português possui uma longa tradição em matéria do ilícito contraordenacional (o RGCO, desde 1982), sendo que ele confere um maior número de garantias ao arguido do que o direito administrativo. Também por isso dissemos atrás que se o direito das contraordenações está mais próximo de algum direito, ele não é seguramente o direito administrativo, mas sim o direito penal e, concomitantemente, o direito processual penal.

Posto isto e sabendo que não fomos exaustivos na análise que fizemos quanto ao RJC, importa levantar aqui uma dúvida já suscitada por outros autores e que é igualmente válida para qualquer outro direito regulador. Vimos que, regra geral, as infrações ao direito da concorrência constituem contraordenações, o que significa que a aplicação da sanção (a coima) pertence à entidade reguladora e não aos tribunais. Na verdade, como também dissemos, estes só intervirão na hipótese de o infrator não se conformar com a decisão condenatória proferida pelo regulador, hipótese em que impugna judicialmente a decisão para um tribunal de competência especializada. No entanto, Marques, depois de uma análise aprofundada sobre o direito da concorrência, conclui que alguns ilícitos como, por exemplo, os cartéis, deveriam ser considerados crimes e não contraordenações.

Com efeito, este autor chega a esta conclusão atendendo aos cânones que impõem a criminalização da ofensa a um bem jurídico (Marques, 2019, p. 449-451), assim se juntando a alguma doutrina internacional referida por Dias e Loureiro (2017, p. 815). Relativamente à infração que sanciona os cartéis, como nos recordam estes dois autores, é certo que nos deparamos com dois modelos contrapostos: de um lado, temos o da UE, instituição que não criminaliza esta conduta, modelo seguido pelo direito português; do outro, o dos EUA, que classifica como crime a formação do cartel desde o designado Sherman Act (Dias e Loureiro, 2017, p. 815).

Que dizer desta dualidade de critério na hora de sancionar os cartéis? Uma coisa tão simples quanto esta: quando uma conduta constitua uma infração e deva ser criminalizada (porque protege bens jurídicos com dignidade penal e porque se verificam os demais pressupostos para a sua criminalização), se o legislador criar não um crime, mas uma contraordenação, então estaremos perante uma norma inconstitucional, pois o direito contraordenacional, quer sob o ponto de vista substantivo, quer sob o ponto de vista processual, é menos garantístico do que o penal. Da mesma forma que, se uma conduta dever constituir uma contraordenação (e, assim, ser sancionada com uma coima e não com uma pena), estamos, de novo, perante uma inconstitucionalidade, porquanto o legislador impõe, através do crime, as suas penas, sanções essas mais gravosas do que as necessárias para aquele caso. Daqui resulta a violação do princípio da proporcionalidade.

Outra reflexão que não podemos deixar de aqui fazer e que se prende não tanto com aspetos substantivos, mas mais processuais e procedimentais, vem a propósito de Marques se 
questionar se a AdC, "num modelo contraordenacional e enquanto entidade administrativa, não se encontrará munida de um exageradamente reforçado catálogo de meios de obtenção de prova, passível de compressão de direitos fundamentais, que, por princípio, não deveria ocorrer em tal natureza de procedimento" (Marques, 2019, p. 453).

Quanto a esta inquietação de Marques, apraz-nos dizer que embora defendamos que os reguladores devem possuir poderes musculados, é preciso que o RJC, em particular, e qualquer outro regime em geral, não conceda poderes processuais penais próprios das autoridades judiciárias, quando estejam em causa direitos, liberdades e garantias dos infratores. Nesse caso, a decisão deve caber a uma destas autoridades, assim se validando provas, à semelhança do que se faz no âmbito do direito processual penal.

Por esse motivo, são bem pertinentes e atuais as considerações de Dias e Pereira (2019, p. 97), quando nos recordam que "os procedimentos pré-administrativos de préinquérito colidem" com a Constituição da República Portuguesa, porque a titularidade da ação penal pertence ao Ministério Público (MP) e porque ela consagra, para o processo penal, uma estrutura acusatória. Segundo os autores, colidem ainda com a lei, na medida em que contrariam a norma do código de processo penal que incumbe ao MP a promoção do processo penal. Estas palavras, aliadas às de Mendes, justamente quanto à estrutura do processo contraordenacional, fazem-nos refletir. E se é certo que propomos a diferenciação dos órgãos dentro da entidade reguladora para mitigar os efeitos do processo contraordenacional, certo é também que alinhamos pelo mesmo diapasão de Marques. Por isso, julgamos dever chamar a atenção para também, por aqui, se rever o RGCO e, dentro da fase organicamente administrativa, fazer intervir em alguns casos o MP, noutros, o juiz e, noutros ainda, ambos.

Acresce ainda que os regimes sancionatórios das atividades reguladas, como é o caso do direito da concorrência, não deveriam consentir aproximações ao CPA, pois que este não tem pendor sancionatório e, em muitos casos, não oferece garantias cabais aos infratores. Mais ainda: acompanhando Dias e Loureiro (2017, p. 853), podemos e devemos afirmar que a sanção pecuniária compulsória é uma manifestação punitiva própria do direito civil e desconhecida do direito penal e do direito das contraordenações. É, ainda com os autores, uma sanção civil destinada a forçar o devedor a cumprir a obrigação em falta.

É também criticável que as contraordenações, em matéria de coimas, não possuam um limite mínimo e máximo com valores certos, antes se socorrendo da percentagem do valor de negócios para os fixar. Mais criticável, porém, é o facto de o legislador de 2012, no âmbito da determinação da medida da coima, deixar de se referir à percentagem do volume de negócios do ano anterior, a fim de encontrar o valor máximo da coima, para passar a reportar-se agora ao volume de negócios do exercício imediatamente anterior à decisão condenatória. Com efeito, como bem assinala Dias, tal volume de negócios não tem relação com a prática da infração. Neste sentido, Dias acrescenta que, embora o legislador goze de uma "ampla margem na definição dos montantes das coimas", "a proporcionalidade requer que essa definição obedeça não exclusiva, mas principalmente, a uma ponderação sobre a gravidade do ilícito e da culpa de cada infracção" (Dias, 2018, p. 60). A propósito deste sistema, o autor acrescenta igualmente que ele conduz a valores extremamente variáveis, consoante a empresa em questão (Dias, 2018, p. 60 e 61). Uma outra crítica a este sistema: em obediência ao princípio da reserva de lei, os limites mínimos e máximos das coimas devem estar previstos numa lei em sentido estrito. E, por assim ser, não nos parece que o n. 8 do artigo $69 .^{\circ}$ cumpra esta exigência ao dispor que a AdC adota "linhas de orientação contendo a metodologia a utilizar para aplicação das coimas".

Mais uma crítica em sede deste RJC reside no facto de se introduzirem mecanismos que parecem pretender que o processo culmine não com uma condenação justa, mas antes por acordo, muitas vezes conseguido com recurso à denúncia. Referimo-nos aos programas de clemência. Assim, nos termos do artigo $75^{\circ}$ do RJC, o infrator pode beneficiar de uma 
dispensa de coima no âmbito de processos por contraordenação referentes, entre outros, a acordo ou práticas concertadas, quando "revele a sua participação num alegado acordo ou prática concertada, desde que essa empresa seja a primeira a fornecer informações e elementos de prova" relevantes para o desenrolar de um processo contraordenacional. Por sua vez, já não há dispensa de aplicação da coima para infratores que não sejam os primeiros a denunciar a infração, mas sim uma redução da mencionada coima, nos termos do artigo 78. , desde que colaborem de forma ativa com a AdC. De notar que a redução da percentagem que diminui a coima vai diminuindo consoante a empresa seja a primeira, a segunda e as seguintes a fornecer elementos relevantes, beneficiando, respetivamente, de reduções de $30 \%$ a $50 \%$, de $20 \%$ a $30 \%$ e de uma redução até $20 \%$.

Uma última nota para acompanharmos Marques na crítica que faz ao traçado do procedimento de transação, previsto no artigo 22. ${ }^{\circ}$. Segundo o autor, estamos perante um procedimento de transação que se reconduz "simplesmente a uma ideia de negociação da sanção, com vista à sua redução", entre a AdC e a empresa visada, tratando-se de uma decisão irrecorrível (Marques, 2019, p. 263).

É, por isso, pertinente, no âmbito da globalização e da europeização do direito, quer no direito da concorrência, quer em qualquer outro, sobretudo se ele comportar uma vertente sancionatória, que atendamos às especificidades dos direitos internos face ao da UE e deste face ao dos EUA. Na verdade, nas emblemáticas palavras de Marques: apenas assim evitaremos a incongruência entre "penal norte-americano-administrativo UE" resultante da "tendência para «importação em segunda linha» de soluções do DEC [Direito Europeu da Concorrência] que correspondem, elas próprias, a soluções transplantadas do ordenamento jurídico norte-americano" (Marques, 2019, p. 453).

\section{CONCLUSÃO}

Não estamos seguros de que o RJC tenha conseguido alcançar os desideratos impostos no MoU da troika. Terminamos, outrossim, sem certeza de que a europeização e a globalização tenham tido a função que se lhes pede, i.e., dar uma resposta conjunta e concertada e harmónica sob o ponto de vista de cada direito interno. Afinal não podemos esquecer que todo o direito não pode provir apenas de uma única fonte de poder, ou de única soberania. "É pois, necessário considerar a possibilidade de ter um direito mais amplo ou mais difuso, criando um conceito de direito que torne possível a sobreposição e interacção de vários sistemas jurídicos sem necessariamente pressupor um sistema de subordinação ou de hierarquia, quer entre eles quer com outros sistemas". Assim, a sobreposição de direito interno e internacional, de forma gradual, encaminha os juristas, também gradualmente, para a formulação de uma constituição mundial, constituição que assentará, sobretudo, "em critérios compartilhados, na coordenação e na subsidiariedade" (Jáuregui, 2013, p. 194 e 195).

Neste caso, da superação da crise económico-financeira, inserida no Estado Regulador e no seu direito sancionatório, ouçamos as palavras de Geithner e Paulson Jr.: o "inimigo está esquecido" (se bem interpretamos as palavras dos autores, com a expressão "inimigos" referem-se à crise e aos seus efeitos). Porém, ainda com os autores, também nós "acreditamos que a primeira regra para uma reforma financeira adicional deve ser hipocrática: (...) devemos ter atenção, mesmo quando reajustamos algumas das reformas pós-crise, para que não se permita um enfraquecimento geral das defesas mais poderosas contra a crise". Ainda em jeito de aviso, escrevem, "quando os tempos estão bons, os perigos de retroceder podem parecer insignificantes. Mas os custos da pior crise financeira podem ser tão grandes que deve haver um esforço sério por medidas ainda mais fortes, tanto para evitá-las, como para mitigálas, quando ocorrerem" (Geithner e Paulson Jr., 2019, p. 126). E, atualmente, dispomos já de um conjunto de ferramentas que então não conhecíamos. Saibamos globalizá-las, mas com 
respeito pelas diferenças dos diferentes ordenamentos jurídicos, americanos, europeus, comunitários e nacionais.

Ainda em jeito de conclusão, impõem-se mais duas pequenas notas: a primeira, para destacar que o direito sancionatório deve existir. Todavia, a aplicação de sanções efetivas e eficazes apenas deve ter lugar depois de verificados alguns pressupostos que reputamos essenciais: a) os infratores devem ser julgados no âmbito de processos justos e equitativos, com medidas que respeitem a legalidade, sobretudo quando estejam em causa direitos fundamentais; b) o decurso do processo deve ser claro e, tanto quanto possível, aproximar-se do processo penal e não do procedimento administrativo, pois só o primeiro permite a cabal proteção dos mencionados direitos fundamentais; c) as sanções devem respeitar o princípio da determinabilidade, pois só assim os infratores poderão livre e conscientemente decidir entre praticar, ou não, a infração; d) o princípio da proporcionalidade entre infrações e sanções deve ser ponderado, e a determinação do valor económico destas últimas não pode, em caso algum, constituir uma "pena de morte" para o agente económico-financeiro. Por esse motivo, deve existir uma correta ponderação quanto aos critérios a observar na determinação da medida da sanção, nomeadamente, a intensidade da culpa, as circunstâncias em que ela foi praticada, as condições económicas do infrator, entre outras; e) o lucro obtido com a prática da infração, tal como já há muito defendemos (Vilela, 2013, p. 364 e 365), não se deve repercutir no valor da coima, mas ser retirado ao infrator enquanto efeito da condenação; f) ao longo do processo sancionatório, deve ser assegurado ao infrator o direito de participação ativa no processo e o de um direito de defesa prévio a qualquer decisão que contra si venha a ser proferida.

Ao elencarmos todos estes pontos, estamos a chamar a atenção para a necessidade de uma correta classificação das infrações, seja enquanto crimes, seja enquanto contraordenações, infrações criadas pelo direito alemão e há muito existentes em Portugal. Só estas duas infrações, com o seu respetivo regime substantivo e processual, permitem assegurar os pontos que exemplificativamente deixámos registados.

Logo, a regulação efetuada pelos reguladores tem contribuído para a superação da crise, do mesmo modo que a necessidade de existência de programas de compliance, enquanto medida de autorregulação, também tem desempenhado um papel positivo, sendo certo que, em Portugal, o setor empresarial tem revelado atenção para a importância de instituírem programas de compliance e de "governação responsável" (Mendes 2018, p. 19).

A segunda conclusão é a de aplaudir que os Estados soberanos beneficiem da vigilância exercida por todos os reguladores, embora com respeito pelos princípios básicos que acima assinalámos exemplificativamente. Todavia, já se clama pela intervenção do Estado soberano, da UE, das suas instituições, do FMI. Clama-se para que intervenham na economia, que lhe injetem capital, porque, afinal, já estamos a sofrer os efeitos tenebrosos do COVID-19. Não só na saúde de todos nós, como no âmbito económico-financeiro. Tudo a clamar urgentemente a reequacionação do que já foi feito.

\section{REFERÊNCIAS}

ARNAULD, André-Jean. A globalização - um desafio ao papel regulador do Estado? In: GONÇALVES, Maria Eduarda, GUIBENTIF, Pierre. Novos Territórios do Direito Europeização, Globalização e Transformação da Regulação Jurídica. Estoril: Princípia, 2008.

BERNARKE, Ben S., GEITHNERM Timothy F., PAULSON JR., Henry M. Firefighting, The financial crisis and its lessons. Profile Books Ltd.: Great Britain, Penguin Books: USA, 2019. 
COSTA, Sandra Isabel Simão da. Impacto da crise na performance económico-financeira das Empresas. Setúbal: Instituto Politécnico de Setúbal. 2014. Disponível em: https://comum.rcaap.pt/bitstream/10400.26/7946/1/Disserta\%C3\%A7\%C3\%A3o\%20Sandra \%20PDF\%20corrigido.pdf; Acesso em: 15/03/2020

DIAS, Augusto Silva; PEREIRA, Rui Soares. Sobre a Validade de Procedimentos Administrativos Prévios ao Inquérito e de Fases Administrativas Preliminares no Processo Penal. Almedina: Coimbra, 2019

DIAS, Augusto Silva. Direito das Contra-Ordenações. Almedina: Coimbra, 2018

DIAS, Jorge de Figueiredo; LOUREIRO, Flávia. Sanções Pecuniárias Compulsórias. In: PORTO, Manuel Lopes et al. Lei da Concorrência: Comentário Conimbricense. Almedina: Coimbra, 2017.

JÁUREDI, Gurutz. (2013). Uma nova ordem política para o século XXI: dos governos dos Estados à governação mundial. In: INNERARITU, Daniel; SOLANA, Javier. A

Humanidade Ameaçada: a Gestão dos Riscos Globais. Teodolito: Lisboa, 2013.

MARQUES, Nuno Castro. Contributo para a autonomia do direito nacional da concorrência, em particular na criminalização dos cartéis. Universidade Católica Editora: Porto, 2019.

Memorando de entendimento sobre as condicionalidades de política económica, de 17 de Maio de 2011. (2011) consultado 15.03.2020: https://aventar.eu/2011/05/04/memorando-datroika-em-portugues/;

MENDES, Paulo de Sousa. O procedimento sancionatório especial por infracções às regras de concorrência. In: PALMA, Maria Fernanda et al. Direito Sancionatório das Autoridades Reguladoras. Coimbra Editora, Coimbra, 2009.

MENDES, Paulo de Sousa (2018). Law Enforcement \& Compliance. In: PALMA, Maria Fernanda et al. Estudos sobre Law Enforcement, Compliance e Direito Penal. Coimbra: Almedina, 2018.

MORAIS, Carlos Blanco. A Lei-Quadro das Entidades Reguladoras e o seu Estatuto de

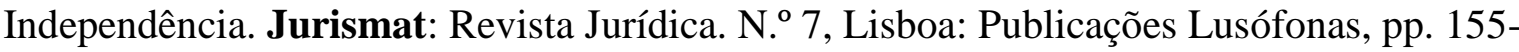
167, 2015. Disponível em:

http://recil.grupolusofona.pt/bitstream/handle/10437/8108/A\%20LeiQuadro\%20das\%20Entid ades\%20Reguladoras.pdf?sequence=1. Acesso em: 06 mar. 2020.

SILVA SÁNCHEZ, Jesús-Maria. (2015). Derecho penal regulatório?. InDret, N.o 2. Disponível em: https://www.raco.cat/index.php/InDret/article/view/293084. Acesso em 09 mar. 2020

SOARES, António Goucha. A europeização do ordenamento jurídico - O Direito da Concorrência. In: GONÇALVES, Maria Eduarda; GUIBENTIF, Pierre. Novos Territórios do Direito - Europeização, Globalização e Transformação da Regulação Jurídica. Estoril: Princípia, 2008. 
TELES, Patrícia Galvão. Globalização e novas fronteiras do Direito Internacional. In: GONÇALVES, Maria Eduarda; GUIBENTIF, Pierre. Novos Territórios do Direito Europeização, Globalização e Transformação da Regulação Jurídica. Estoril: Princípia, 2008.

VILAÇA, José Luís da Cruz; GOMES, José Luís Caramelo.Objeto Art. 1. ․ In: PORTO, Manuel Lopes et al. Lei da Concorrência: Comentário Conimbricense. Almedina: Coimbra, 2017.

VILELA, Alexandra. O Direito de Mera Ordenação Social: entre a ideia de «recorrência»e a de «erosão» do Direito Penal Clássico, Coimbra Editora, Coimbra. 2013.

VILELA, Alexandra. O direito contra-ordenacional: um direito com futuro. Anatomia do Crime - Revista de Ciências Jurídico-Criminais, n. ${ }^{\circ}$ 2, 2015, p.149-162,

VILELA, Alexandra. A fase jurisdicional do processo contraordenacional. Anatomia do Crime - Revista de Ciências Jurídico-Criminais, n. o 5, 2017, p. 129-144;

VILELA, Alexandra. A responsabilidade contra-ordenacional da pessoa colectiva no contexto do "Estado Regulador". In: PALMA, Maria Fernanda et al. Estudos sobre Law

Enforcement, Compliance e Direito Penal. Coimbra: Almedina, 2018. 